\title{
Benjamin Barreto da Silva Araújo um compositor brasileiro
}

\author{
Lenine Alves dos Santos ${ }^{1}$
}

Resumo

Levantamento biográfico, organização e comentário crítico do repertório de canções de Benjamin Barreto da Silva Araújo (1902-1985), pianista, regente, arranjador, professor e compositor brasileiro que teve importante atuação na cena musical clássica e popular do Brasil. Musicou vários poemas de autores ligados ao movimento modernista, ficando sua obra desconhecida após sua morte. Pesquisa bibliográfica, técnicas de análise musical e de inter-relação texto-música são utilizadas para evidenciar o valor artístico de suas canções e dar aos intérpretes da música de câmera vocal brasileira conhecimento de sua existência ${ }^{2}$.

Palavras - chave

Música Brasileira, Benjamin Silva Araújo, canção.

Recebido em 26 de agosto de 2013

Aprovado em 12 de fevereiro de 2014

SANTOS, Lenine Alves dos. Benjamin Barreto da Silva Araújo: um compositor brasileiro. Revista do Instituto de Estudos Brasileiros, BrasiL, N. 59, P. 311-328, dez. 2014.

DOI: HTTP://DX.DOI.ORG/10.11606/ISSN.2316-901X.v0159P311-328

1 Universidade Federal do Estado do Rio de Janeiro (Unirio, Rio de Janeiro, RJ, Brasil).

2 O presente artigo foi publicado em versão resumida nos Anais do XXIII Congresso da ANPPOM de 2013. Ver: SANTOS, Lenine Alves dos. A canção de Benjamin Barreto da Silva Araújo: resgate da obra vocal de um compositor brasileiro. Anais do XXIII Congresso da ANPPOM, Natal/RN, 2013. Disponível em: http://ww w.anppom.com. br/congressos/index.php/ANPPOM2013/Escritos2013/paper/view/2020/446. Acesso em: 11 fev. 2014 . 


\title{
Benjamin Barreto da Silva Araújo a Brazilian Composer
}

\section{Lenine Alves dos Santos}

\begin{abstract}
Biographical survey, organization and critical review of the repertoire of songs by Benjamin Barreto da Silva Araújo (1902-1985), a pianist, conductor, arranger, teacher and Brazilian composer. He had an important role in both the classical and popular music scene in Brazil. He set to music several poems by authors connected to the modernist movement. His work remained unknown after his death. Bibliographical search, technical analysis and the relationship between music and text are used to highlight the artistic value of his songs and introduce them to the interpreters of Brazilian vocal chamber music.
\end{abstract}

Keywords

Brazilian Music, Benjamin Silva Araújo, song. 

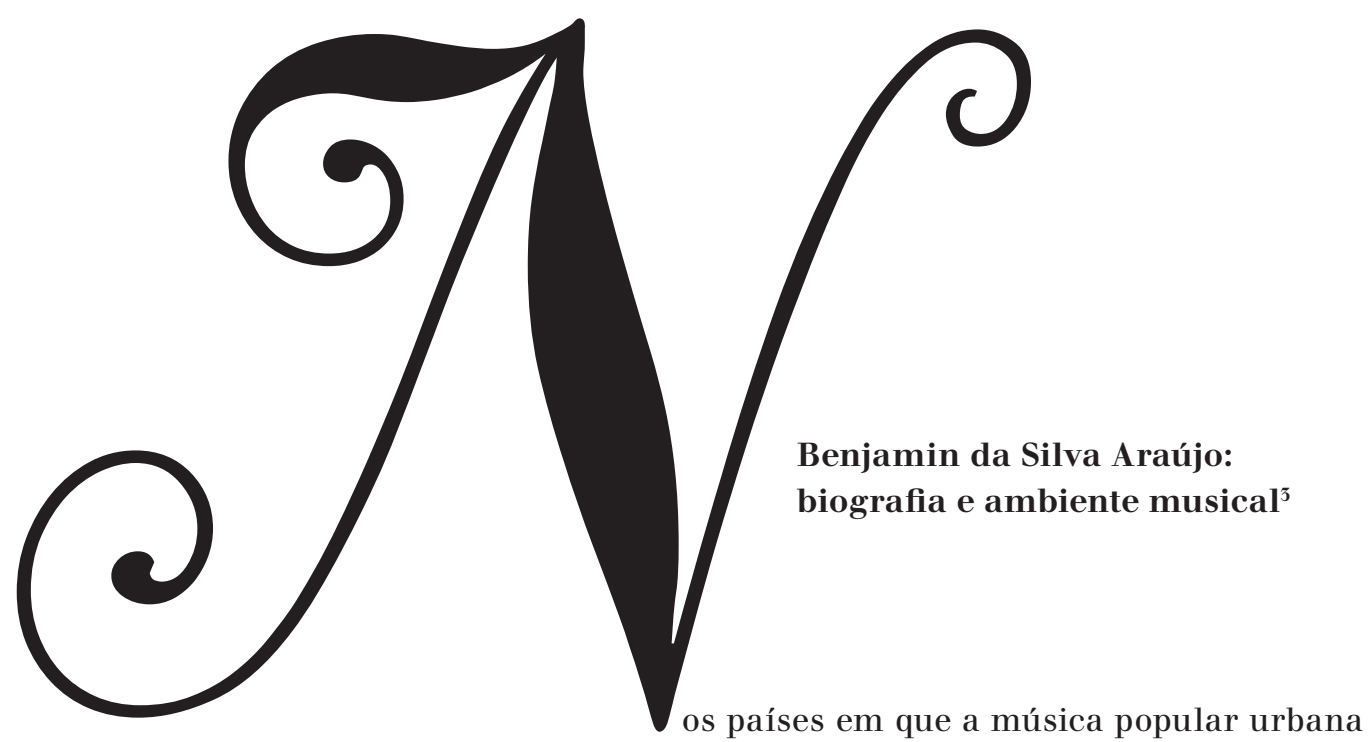

assume a importância social, cultural, política e econômica que tem em países como o Brasil ou os Estados Unidos da América, é comum surgirem talentos na área da composição cuja circunscrição a apenas um ambiente musical se faz impossível. Assim sendo, compositores como George Gershwhin (1898-1937) ou Leonard Bernstein (1918-1990) tiveram nos EUA atuação tão importante na música de concerto quanto na música popular, e suas canções têm sido interpretadas e gravadas, através dos tempos, por cantores líricos e populares ${ }^{4}$.

O compositor carioca Benjamin Barreto da Silva Araújo (19021985) é um perfeito exemplo deste tipo de criador que, a exemplo de vários compositores brasileiros como Waldemar Henrique (1905-1995), Heckel Tavarez (1896-1969), Marcelo Tupinambá (1889-1953) ou Radamés Gnattali (1906-1998), deve ter sua obra analisada simultaneamente no ambiente da música de concerto e da música popular. Benjamin compôs, além de uma literatura pianística de linguagem bastante complexa, canções populares que foram interpretadas por cantoras da 'era do rádio',

3 Devido à quase inexistência de bibliografia referente ao compositor, parte das informações biográficas contidas neste texto foram obtidas através de entrevistas realizadas com pessoas que com ele conviveram, como Luiz Viera Silva Araújo (1947) - seu sobrinho; Paulo de Azevedo Lemes Barbosa (1954) - ex-aluno e tutor do seu acervo; Nancy Bueno de Almeida (1954) - pianista que interpretou várias das obras do compositor sob sua orientação; Lenice Prioli (1929) - cantora que realizou vários recitais com o seu cancioneiro; além de entrevista com o próprio compositor, concedida aos jornalistas Sérgio Gomes e Osvaldo Luiz Vitta em 18 de agosto de 1977. Também foram utilizadas informações advindas de memorial escrito pelo próprio compositor, assim como documentos, partituras e correspondências constantes de seu arquivo pessoal.

4 PEYSER, Joan. Bernstein, a biography. New York: Beech Tree Books, 1987. 
como Aracy Cortes (1904-1985)5 e Linda Batista (1919-1988), e perfeitos exemplos de canção de câmera, várias delas dedicadas a artistas célebres desta tradição, como a cantora e professora Madalena Lébeis (1912-1984) e o meio-soprano Lenice Prioli (1929), tendo sido por elas estreadas ${ }^{6}$. No entanto, após sua morte, sua obra ficou esquecida e inacessível aos intérpretes e estudiosos de nossa música.

Benjamin Barreto da Silva Araújo, ou 'Maestro Benja' - como viria a ser chamado entre seus pares, nasceu na cidade do Rio de Janeiro, à época Capital Federal, em 31 de outubro de 1902. Sua família, tanto por parte do pai - os 'Silva Araújo' - quanto da mãe - os 'Sá Barreto', contava com representantes que há muito se distinguiam na vida política, cultural e econômica da cidade, a exemplo de seu avô paterno, o imigrante português Francisco Manuel da Silva Araújo (s.d), que se destacou por seu pioneirismo na indústria farmacêutica no Brasil, tendo fundado a empresa famosa pelo seu 'Vinho Reconstituinte Silva Araújo'. 7 Seu avô materno Cândido Pereira Barreto (s.d), foi deputado pela província do Rio de Janeiro e irmão de um médico notável, Luiz Pereira Barreto (1840-1923), que atuou na erradicação de epidemias e nas campanhas de vacinação no Rio de Janeiro ${ }^{8}$.

A música foi importante e constante em seu ambiente familiar, sendo tanto sua avó paterna, Gabriela de Sá da Silva Araújo (s.d), quanto a materna, Virgínia de Sá Barreto (s.d), pianistas de formação técnica e musical consistente, embora não profissionais. Seu pai, Bráulio da Silva Araújo, ainda que não lesse música, tocava ao piano obras longas e

5 O samba "Que é que é”, de autoria de Benjamin Silva Araújo, foi dos maiores sucessos de Aracy Cortes (1904-1985), gravado em 1932 e relançado em 1995 pelo selo 'Revivendo'. Ver: “O que é que é”. Aracy Cortes. Músicas Brasileiras V. 4. Faixa 2. RV o88. Curitiba: Revivendo, 1995. 1 CD.

6 Madalena Lébeis (1912-1984) foi aluna de Vera Janacopoulos (1892-1955), cantora de grande importância para a divulgação das canções de compositores brasileiros no exterior, principalmente as de Heitor Villa-Lobos. Lébeis registrou num diário suas aulas com Janacopoulos em seu período de formação, entre 1937 e 1955, legando-nos um dos mais importantes documentos sobre a pedagogia do canto e a canção de câmera em sua época. Mais tarde foi professora do meio-soprano Lenice Prioli (1929), que perpetuou em sua carreira a veia artística camerística e a escola de suas antecessoras. Ver: VASCONCELOS, Emerson Adriano Gomes. Magdalena Lébeis e o registro sistemático de um processo pedagógico: algumas análises. 2012. 198 p. Dissertação (Mestrado em Processos de Criação Musical) - Escola de Comunicações e Artes, Universidade de São Paulo, 2012.

7 EDLER, Flávio Coelho. Boticas \& pharmacias: uma história ilustrada da farmácia no Brasil. Rio de Janeiro: Editora Casa da Palavra, 2006.

8 ALONSO, Ângela. O positivismo de Luís Pereira Barreto e o pensamento brasileiro no século XIX. Coleção Documentos. Série Teoria Política. IEA/USP, São Paulo, v. o9, p. 1-18, 1995 . 
complexas, principalmente das operetas tão em voga à época, e sua mãe, Eurydice de Sá Barreto (s.d), além de pianista, estudou viola e tocou, na primeira década do século $X X$, na Orquestra de Câmera de Nova Friburgo, conduzida por seu irmão, o pianista e compositor Homero de Sá Barreto (1884-1924), tio de Benjamim. Consta que o $1^{\circ}$ quarteto de cordas de Heitor Villa-Lobos (1887-1959), foi estreado na residência do Maestro Homero de Sá Barreto em Nova Friburgo, e que este privava da amizade de vários artistas e intelectuais da época, dentre eles o próprio Villa-Lobos e Menotti Del Picchia (1892-1988) ${ }^{9}$. A convivência com o tio compositor, bem como com os outros músicos da família, cedo despertaram no menino Benjamin o gosto pela criação e pela performance artística, sendo determinantes para o seu futuro direcionamento profissional, bem como o de seus irmãos Armando Silva Araújo (1905-1988) pianista e compositor - e Aloísio Silva Araújo (s.d) - pianista, radialista e compositor, integrou o Grupo dos Calungas, liderado pelo violonista e compositor Aníbal Augusto Sardinha, o 'Garoto' (1915-1955) ${ }^{10}$.

Benjamin da Silva Araújo iniciou seus estudos de piano e teoria com o professor Higino Mancini (s.d), na cidade de Nova Friburgo (RJ), em 1912, tendo sido aluno também de Rinalda Côrtes (s.d) quando se transferiu para o Rio de Janeiro em 1915. As duas cidades se alternaram em importância na primeira infância e adolescência do jovem músico. Ao terminar o curso ginasial, ingressou no Instituto Nacional de Música - hoje Universidade Federal do Rio de Janeiro - onde foi aluno do compositor Henrique Oswald (1852-1931). Ao fim do curso foi obrigado a interromper os estudos musicais devido ao serviço militar, tendo neste período grande experiência atuando com o clube de choro 'Mimosas Cravinas de Botafogo', tocando em saraus, sessões de cinema mudo e bailes populares. Em 1925, mudou-se para a cidade de Ribeirão Preto (SP), iniciando intensa atividade profissional na cidade onde seu tio Homero já havia se estabelecido anteriormente. Ali lecionou piano, canto orfeônico, compôs suas primeiras obras - inclusive na área da canção de concerto - e realizou os primeiros arranjos orquestrais, executados

9 4. Homero de Sá Barreto (1884-1924) deixou uma pequena, mas consistente obra musical, da qual consta a ópera 'Jaty', que foi executada no Rio de Janeiro após a morte do compositor sob iniciativa de Francisco Braga (1868-1945) e Heitor Villa-Lobos (1887-1959). Ver: FERNANDES, Thaty Mariana. A música em Ribeirão Preto: manifestações do início do séc. XX. Ribeirão Preto: Fundação Instituto do Livro, 2011. Ver: Diário da Manhã, Ribeirão Preto-SP, artigo de 5 de dezembro de 1924. Ver: BARRETO, Homero de Sá. Biografia. Academia Brasileira de Música. Disponível em: http://www.abmusica.org.br/html/patrono/patrz8.html. Acesso: 11 fev. 2014.

10 H. MELLO, Jorge . Vida e música de Garoto. São Paulo: Edições SESC-SP, 2012. 
pela Sociedade Sinfônica daquela cidade sob regência do maestro Ignácio Stábile (1889-1955) ${ }^{11}$.

Sua vinda para a cidade de São Paulo, em 1942, proporcionou-lhe ingressar na Rádio Record, a princípio como pianista, mas tendo logo seus talentos de regente e arranjador reconhecidos. Em 1946, retornou ao Rio de Janeiro, atraído pelo ambiente musical efervescente, pela possibilidade de atuar como pianista, compositor e regente em várias companhias de teatro musical da cidade e, simultaneamente, de lecionar canto orfeônico no Instituto La-Fayette e de reger as orquestras da Rádio Mayrink Veiga e da TV Continental. A cidade de São Paulo viria a atraí-lo novamente em 1949, quando do convite para atuar como diretor musical do filme "Luar do Sertão" (1949), de Mário Civelli (1922-1993), e na capital paulista permaneceu, trabalhando com as orquestras da Rádio Bandeirantes e da TV Record de 1949 a 1965.

No ano de 1965 o compositor mudou-se para a cidade de Resende, no estado do Rio de Janeiro, à procura de um ambiente mais tranqüilo, acometido que estava pela intensificação de problemas respiratórios que sempre o acompanharam, e que a cidade grande tendia a aprofundar. Naquela cidade, fundou a Academia Resendense de Artes e a Sociedade Coral Santa Rosa, participando ativamente da vida social da cidade através de sua produção musical, projetos educacionais e vários artigos publicados em periódicos locais. Em fins de 1972, já com setenta anos de idade e sentindo a deterioração de sua saúde, decidiu mudar-se para São José dos Campos (SP), cidade onde tinha amigos próximos que o acolheram em ambiente familiar, e na qual o clima era mais propício. Ali, dedicou-se ao ensino de piano e à revisão e aprimoramento de suas composições, tornando-se uma figura de referência na vida musical da cidade, que viveu um incremento de sua produção cultural durante sua estadia ali, sendo sua obra pianística e vocal executada por vários intérpretes locais. A familiaridade com os instrumentistas e compositores de música popular, e o talento como compositor e arranjador, o levaram à presidência do Clube do Choro de São Paulo desde sua fundação em 1977 até 1979, segundo a historiadora do Clube, Miranda Nunes de Souza, "por ser uma figura respeitada pelos chorões e agregadora". ${ }^{12}$

11 Ignácio Stabile (1889-1955) - Regente. Natural de Roma, Itália, estudou no conservatório de música de Nápoles e dirigiu várias companhias líricas, estabelecendo-se em Ribeirão Preto-SP a partir de 1938, onde foi regente da Orquestra Sinfônica local até 1955 .

12 SOUZA, Miranda Bartira Tagliari Rodrigues. O Clube do Choro de São Paulo: Arquivo e Memória da Musica Popular na Década de 70. 2009. 255 p. Dissertação (Mestrado em Música). Unesp, 2009, p. 7o. 
Regressou ao Rio de Janeiro de seu nascimento em 1985, aos cuidados da família, debilitado pela idade e pelo agravamento de sua doença respiratória, vindo a falecer no dia 03 de outubro.

\section{O acervo do compositor}

A orientação pedagógica de Benjamin da Silva Araújo durante sua última fase de trabalho foi profissionalmente determinante para vários jovens pianistas e músicos da cidade de São José dos Campos-SP, muitos dos quais não apenas frequentaram suas aulas como privaram de sua amizade. Dentre eles, o pianista Paulo de Azevedo Lemes Barbosa (1954) teve um papel especial, tendo sido seu aluno durante longos anos e devendo a ele seu aprimoramento técnico e uma inserção consistente na vida musical profissional, vindo a se tornar o tutor da obra de Benjamin quando do seu falecimento. Azevedo tem uma intensa atuação na região do Vale do Paraíba como pianista, cantor, professor e gestor cultural. Suas atividades estão concentradas na instituição que leva o nome de 'Centro Cultural Maestro Benjamin Silva Araújo', em homenagem a seu mestre. O centro cultural também abriga o acervo de partituras, textos, documentos e objetos pessoais do compositor, que antes de falecer confiou o material a Paulo Azevedo, contando com os cuidados do músico e amigo.

Os direitos autorais referentes a todo o material estão sob a posse do sobrinho do compositor, Luiz Vieira Silva Araújo (1947), profissional de cinema atuante na cidade do Rio de Janeiro. O Sr. Luiz concordou com o manuseio da obra voltado para estudos acadêmicos e organização para eventual publicação. Paulo Azevedo, por sua vez, generosamente nos abriu acesso a toda a obra do compositor, possibilitando uma primeira catalogação do material ali encontrado.

As obras, cujas datas de composição vão de 1920 a 1977, muitas com revisões posteriores, se dividem em seis categorias principais:

a) Obras para piano:

- 12 Choros para piano solo;

- 2 Prelúdios;

- 7 Mini-Valsas;

- 4. Toadas;

- 3 Cenas Brasilienses;

- 6 Sertanejas;

- 6 Obras para o ensino do piano;

- 1 Choro para piano a quatro mãos;

- 1 Choro para dois pianos. 
Sua literatura para piano abrange várias linguagens, desde uma escrita mais tradicional, herdeira do pianismo europeu do período romântico tardio e início do impressionismo - caso dos prelúdios e valsas - até obras com marcada influência da música popular e folclórica - como os Choros, as Toadas e as Sertanejas. Dentre os Choros, merece destaque o Choro Cromático, que trouxe inovações harmônicas e melódicas ao gênero. Esta obra foi defendida pelo pianista Amilton Godoy (1941) no 'Festival Brasileirinho', um certame dedicado apenas ao choro promovido pela TV Bandeirantes em $1977^{13}$.

b) Música de câmera:

- 1 Obra para violino e piano;

- 1 Obra para violoncelo e piano;

- 1 Obra para violão e piano.

Cabe destacar que a pequena literatura de câmera instrumental é constituída de peças breves, com uma linguagem romântica influenciada pelo melodismo popular brasileiro e a harmonia jazzística, escrita para participação em saraus e reuniões sociais.

c) Composições originais e arranjos para canto e orquestra:

- 20 Obras - compostas quando atuava como maestro nas rádios Mayrink Veiga e Bandeirantes e na TV Record - com textos de vários poetas e letristas como Olavo Bilac (1865-1918), Dias Gomes (1922-1999), Osvaldo Moles (1913-1967), além de arranjos orquestrais de obras célebres para piano.

- 12 Canções originalmente compostas para orquestra e coro ou canto solista, em sua maioria de caráter ufanista, para uso em programas de TV ou Rádio.

É interessante notar que estas obras para orquestra e coro foram criadas de acordo com o gosto musical e do ambiente político da época, quando vários compositores (tanto populares quanto eruditos) criaram obras de caráter patriótico, a exemplo de Heitor Villa-Lobos (1887-1959) em 'Invocação em Defesa da Pátria' ou Ary Barroso (1903-1964), com sua 'Aquarela do Brasil'. ${ }^{14}$ Há reduções para piano e canto de algumas destas obras realizadas pelo próprio compositor.

13 Vide nota 12. p. $74-78$.

14. MACHADO, Maria Célia. Heitor Villa-Lobos. Rio de Janeiro: Livraria Francisco Alves Editora, 1987 . 
d) Fantasias para piano e orquestra:

- Fantasia sobre Onde o céu é mais azul, de Carlos Alberto

Ferreira Braga (1907-2006), mais conhecido sob os pseudônimos de 'João de Barro' ou 'Braguinha'.

- Fantasia sobre Carinhoso, de Alfredo da Rocha Viana Filho (1897-1973), o 'Pixinguinha'.

Mais uma vez trata-se de obras compostas como parte de seu trabalho para orquestras de rádio e TV, geralmente para ser executadas como abertura ou intermezzo de transmissões de programas musicais com cantores diversos.

e) Canções populares:

- 17 canções encontradas até a atual fase de pesquisa, algumas das quais publicadas e registradas em disco.

f) Canções de câmera - 40 canções, separadas em 9 conjuntos ou 'ciclos':

- Canções Românticas - $1^{\mathrm{a}}$ série (3 canções)

- Canções Românticas - 2a série (4 canções)

- Canções Românticas - $3^{\mathrm{a}}$ série (5 canções)

- Canções Românticas - $4^{\mathrm{a}}$ série (4 canções)

- Canções Populares sobre versos de Guilherme de Almeida (4 canções)

- Miniaturas (4 canções)

- Canções esparsas (5 canções)

- Canções Brasilienses (3 canções)

- Outras canções (8 canções)

Nota-se que as canções, seguidas pela obra pianística, constituem o setor mais amplo e consistente da obra do compositor, do ponto de vista da música de concerto, quase todas tendo sido organizadas e revisadas pelo compositor.

Neste artigo concentraremos nossa atenção no repertório de canções de câmera, sobre as quais discorreremos a seguir.

\section{As canções de câmera}

De todas as obras do acervo, as canções seguramente são as que passaram, durante os últimos anos de vida do compositor em São José dos Campos (SP), por uma revisão mais criteriosa, tanto para lapidar 
eventuais conduções melódicas e usos da prosódia, quanto para conferir à parte pianística uma importância maior, harmônica ou melódica, proporcionando às canções um equilíbrio de discurso entre o instrumento e a voz mais condizente com a tradição da canção de câmera. Há casos em que se pode encontrar várias cópias da mesma canção entre manuscritos, cópias e fotocópias - com maior ou menor número de alterações, até se chegar a um exemplar final, geralmente em cópia heliográfica, que o compositor parece ter considerado como a obra finalizada. Este material, bem como a existência de três canções - constantes do conjunto 'Outras Canções' - cujas partes vocais e seus respectivos textos estão escritos diretamente na pauta dupla do piano, nos dão indícios de que o processo composicional de Silva Araújo seguia um processo de criação da melodia a partir do texto, com uma harmonia básica, que mais tarde era submetida a uma realização mais elaborada, sendo que talvez não tenha havido tempo para que as últimas canções passassem por este procedimento completo.

Os nove grupos, totalizando quarenta canções, foram definidos e nomeados pelo próprio compositor, sendo que com uma primeira análise já se pode verificar a possibilidade de considerar alguns desses grupos como 'ciclos' de canções, seja pela unidade temática literária, conseguida musicando um mesmo poeta ou lidando com os mesmos objetos poéticos, seja pelas recorrências melódicas ou harmônicas, que criam uma unidade de discurso que perpassa as diferentes canções. Por hora nos referiremos aos grupos como 'conjuntos de canções', evitando assim uma definição prematura.

Os anos de composição parecem ter menos importância para o seu agrupamento em conjuntos específicos que a temática e a autoria dos textos, visto que se encontram canções em um mesmo conjunto que foram compostas com separação de muitos anos. Os poetas musicados têm, em geral, tradição não somente na poesia como na canção brasileira, como Castro Alves (1847-1871) em O Coração - texto que recebeu uma realização musical recente do compositor paulistano Achille Picchi (1952) - Menotti del Picchia (1892-1988), inclusive do seu poema Amor, também musicado por Marcelo Tupinambá (1889-1953) - e Vicente de Carvalho (1966-1924). Cleómenes de Campos (1895-1968), poeta escolhido por cancionistas como Camargo Guarnieri (1907-1993) e Joubert de Carvalho (1900-1977), e Suzana de Campos (1884-1945), de quem os compositores nacionalistas musicaram tantos poemas, figuram também entre os autores. Há algumas surpresas, como um texto do crítico musical Oscar Guanabarino (1851-1937), e outro do multifacetado Luiz Peixoto (1889-1973), que o musicólogo Vasco Mariz (1921) considera 
"responsável por algumas das mais belas letras da música popular brasileira". ${ }^{15}$ Porém o poeta que tem a preferência de Benjamin da Silva Araújo é, sem dúvida, Guilherme de Almeida (1890-1969), presente com seus versos em onze canções.

A grande identificação do compositor com o poeta campineiro faz-se sentir não apenas pelo número de poemas musicados, mas pelo resultado alcançado no comentário musical meticuloso dos poemas, em obras que demoraram, às vezes, vários anos para ser finalizadas.
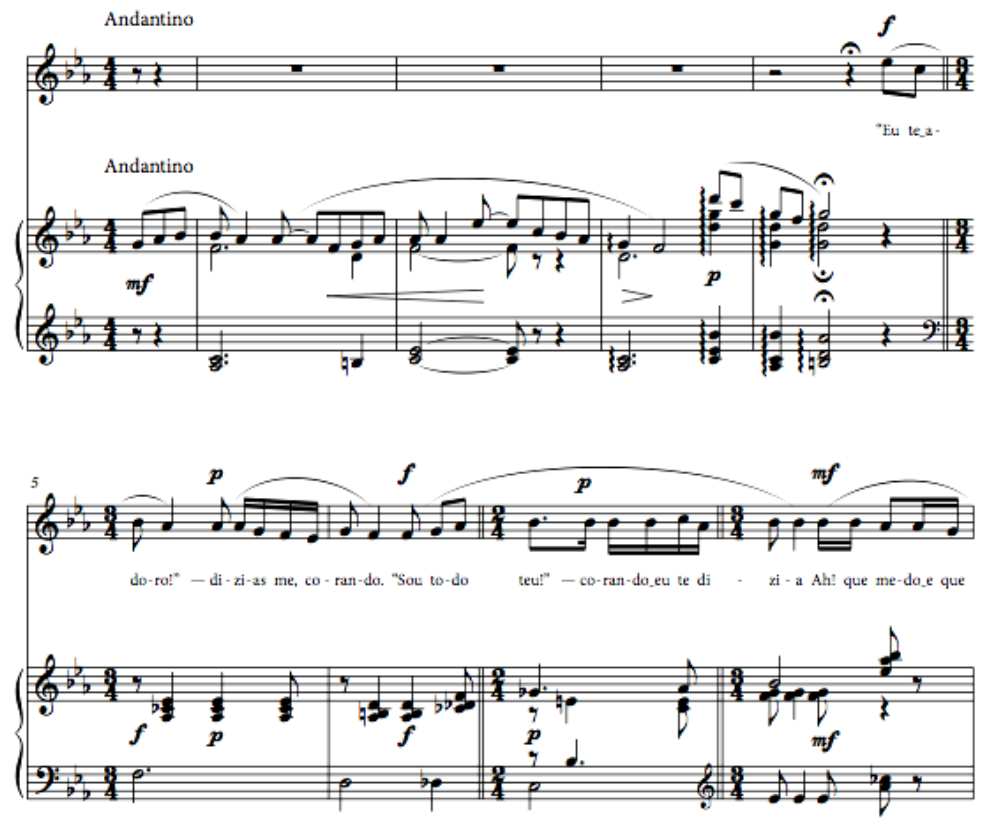

Figura 1: Os oito primeiros compassos da canção "Eu te adoro"16 (1970), da 2a série de 'Canções Românticas', com texto de Guilherme de Almeida (1890-1969).

A linguagem musical é diversa, indo de um equilíbrio formal e uma elaboração harmônica que reportam, em alguns casos, às últimas canções de Lorenzo Fernandez (1897-1948), em outros a uma harmonia quase funcional e simples, similar às das canções de inspiração folclórica de Waldemar Henrique (1905-1995), em outros ainda com uso de incidências melódicas e harmônicas e formais condizentes com o ambiente

15 MARIZ, Vasco. Vida musical. Rio de Janeiro: Civilização Brasileira, 1996. p. 26

I6 ARAÚJO, Benjamin Barreto da Silva. Eu te adoro. Partitura manuscrita. 3 p. Resende-RJ, 1970. 
do choro, do bolero e do samba-canção. De modo geral, a grande versatilidade do compositor pode ser sentida na diversidade de estilos musicais que é capaz de evocar e realizar, impulsionado pelo teor dos textos que elege, alguns deles em idiomas estrangeiros.

Há na maioria das canções modulações constantes para tons homônimos, tons vizinhos, e é recorrente o recurso de terminar a canção na relativa menor do tom principal, no da dominante da tônica ou na dominante da relativa menor.
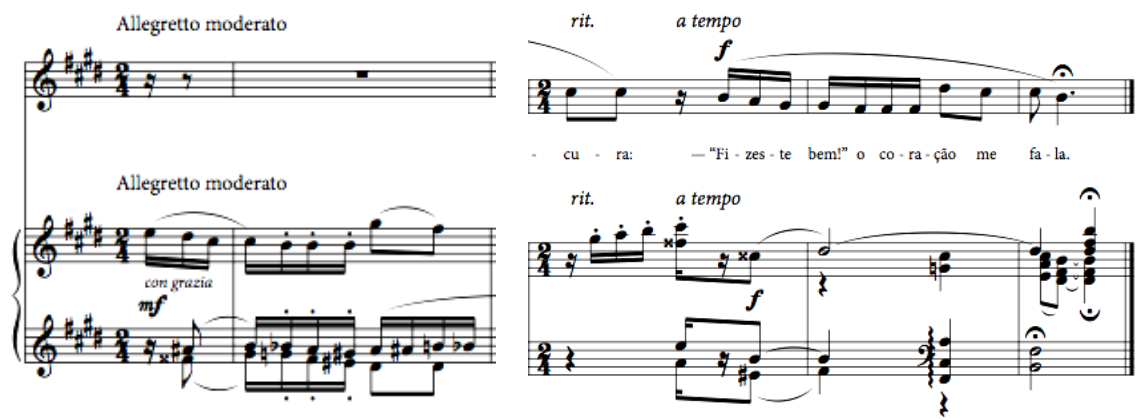

Figura 2: Dois primeiros, seguidos dos três últimos compassos da canção "Dolóra”, ${ }^{17}$ da $3^{\text {a }}$ série de 'Canções Românticas', com texto de Alberto de Oliveira (1857-1937). A canção inicia em Mi Maior, e termina em Si Maior, dominante do tom principal.

As canções em geral são curtas, em sua maioria abrangendo duas páginas de música, com duração média entre um minuto e trinta segundos e dois minutos. Isto se dá pela escolha clara do compositor em não interferir na forma do poema, não repetindo versos ou estrofes, e nem acrescentar trechos pianísticos longos - procedimento comum na composição do Lied - dedicando-se ao comentário musical do texto literário com uma economia de meios cujo resultado se aproxima da declamação. Há o caso das quatro miniaturas, com uma página cada - com duração média de cinquenta segundos - e de canções como "Mal-Me-Quer", da $3^{\text {a }}$ série de 'Canções Românticas', que são um pouco mais extensas, chegando a dois minutos e trinta segundos.

A linha melódica de Benjamin Silva Araújo apresenta grande conhecimento do instrumento vocal, em geral se mantendo dentro da tessitura confortável para um meio-soprano ou barítono leve, o que nos reporta à prática de composição vocal do modernismo nacionalista

17 ARAÚJO, Benjamin Barreto da Silva. Dolóra. Partitura manuscrita. 2 p. Ribeirão Preto: 1927 . 
preconizada por Mário de Andrade (1893-1945), que defendia o uso das regiões médias da voz como mais caracteristicamente brasileiro e mais propício ao entendimento do texto ${ }^{18}$. No entanto, há exceções em canções como "O Coração", cuja extensão alcança um La 4 - escrito na primeira linha suplementar superior da clave de sol - com articulação de texto, uma região bastante aguda mesmo para um soprano. O trabalho prosódico denota grande conhecimento de escansão, permitindo a subversão do metro natural em vários momentos para a obtenção de efeitos musicais.

Um de seus traços estilísticos mais recorrentes é o uso de cromatismos melódicos.

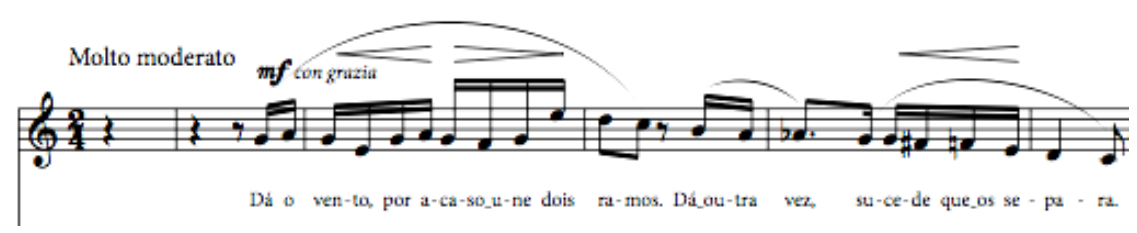

Figura 3: Cinco primeiros compassos da canção "Incoerência", ${ }^{19}$ sobre versos de Alberto de Oliveira (1857-1937), com a segunda frase apresentando cromatismo descendente.

O texto é tratado com especial atenção, com a melodia sempre subordinada às necessidades da declamação.

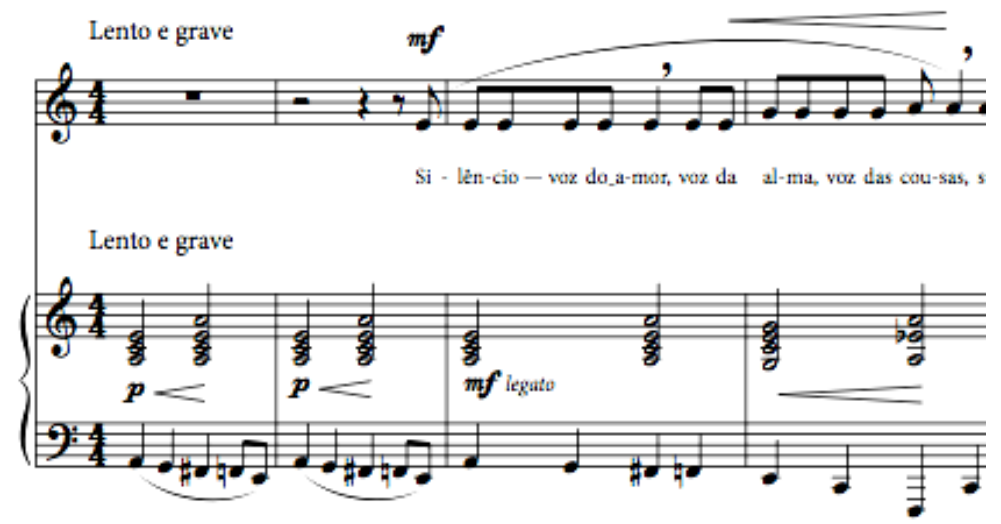

Figura 4: Quatro primeiros compassos de "Silêncio", ${ }^{20}$ com texto de Guilherme de Almeida (1890-1969): tessitura em região média, com escrita da linha vocal sugestiva da declamação.

18 ANDRADE, Mário de. Ensaio sobre a música brasileira. São Paulo: Martins, 1972.

19 AR AÚJO, Benjamin Barreto da Silva. Incoerência. Partitura manuscrita. 2 p. Ribeirão Preto, 1927.

20 ARAÚJO, Benjamin Barreto da Silva. Silêncio. Partitura manuscrita. 2 p. Rio de Janeiro, 1961 . 
A meticulosidade e o respeito no tratamento da palavra traem a grande paixão de Benjamin pela poesia. Seu acervo contém inúmeros volumes de poetas seus contemporâneos, como Alberto de Oliveira (18571937), Mozart Firmeza (1906-1965), Guilherme de Almeida (1890-1969), Menotti del Picchia (1892-1988), entre outros, dos quais extraiu grande parte dos textos que musicou. Também se encontram ali exemplares de obras de sua própria lavra, coleções de poemas que dedicou a amigos e familiares, e que demonstram sua habilidade no tratamento do verso, em geral de caráter romântico, já com influência do modernismo.

Em suas canções o piano raramente assume o protagonismo do discurso musical, na maior parte do tempo secundando com grande cumplicidade o trajeto do eu lírico, sendo a harmonia a matéria principal utilizada para revelar e sublinhar os estados de espírito expressos no texto. No entanto o instrumento às vezes é chamado a ilustrar imagens poéticas específicas.

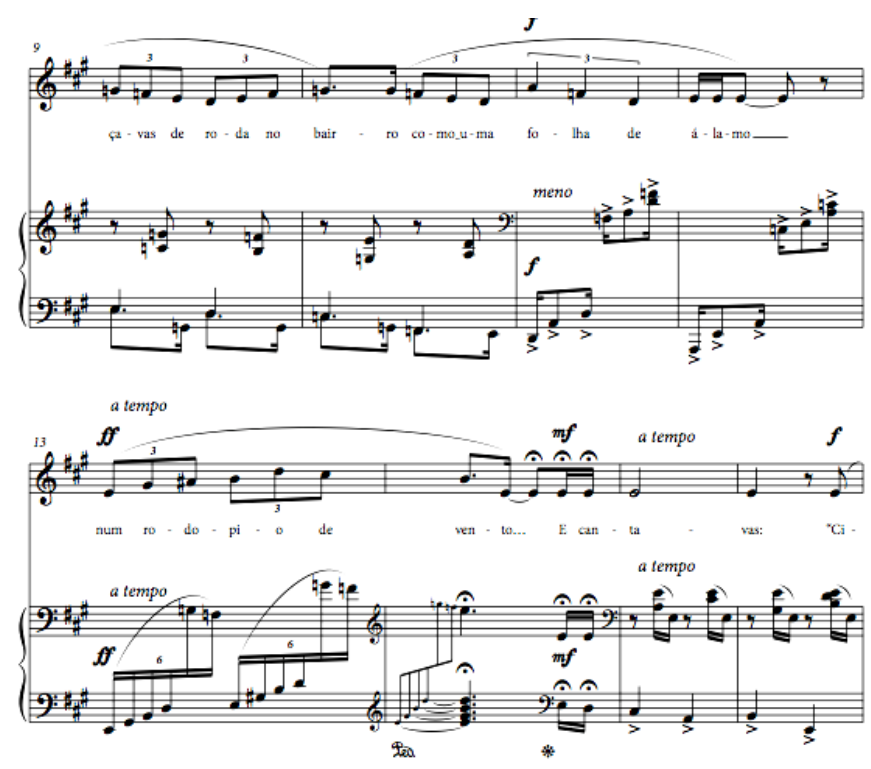

Figura 5: Compassos nove a dezesseis de "Ciranda, Cirandinha", ${ }^{21}$ (1934), com texto de Menotti Del Picchia (1892-1988). O acompanhamento pianístico, que se pontuava discretamente o texto, assume síncopas regulares ao evocar "folhas de álamo”, e desdobra-se em quiálteras rápidas e ascendentes para ilustrar a imagem do texto em "num rodopio de vento".

21 ARAÚJO, Benjamin Barreto da Silva. Ciranda, Cirandinha. Partitura manuscrita. 2 p. Rio de Janeiro, 1934 . 
A seguir, apresentamos a lista completa dos conjuntos de canções com seus respectivos autores:

1) Canções Românticas $-1^{\mathrm{a}}$ Série

Меu Primeiro Amor (1927) Texto: Alberto de Oliveira (1857-1937)

O Coração (1931) Texto: Castro Alves (1847-1971)

Ah! Morra Em Mim Este Amor (1924) - Texto: Alberto de Oliveira (1857-1937)

2) Canções Românticas - $2^{a}$ série

Incoerência (1927) Texto: Alberto de Oliveira (1857-1937)

Alegria (1936) Texto: Mozart Firmeza (s.d)

Felicidade (1934) Texto: Cleomenes de Campos (1895-1968)

Eu Te Adoro! (1970) Texto: Guilherme de Almeida (1890-1969)

3) Canções Românticas - 3a Série

Hesitação (s.d) Texto: Menotti del Picchia (1892-1988)

Dolora (1927) Texto: Alberto de Oliveira (1857-1937)

Cuidado! (s.d) Texto: Guilherme de Almeida (1890-1969)

Mal-Me-Quer (1958) Texto: Guilherme de Almeida (1890-1969)

Hoje Voltas-me o Rosto (1970) Texto: Guilherme de Almeida (1890-1969)

4) Canções Românticas - 4a Série

Felicidade (1969) Texto: Guilherme de Almeida (1890-1969)

Silêncio (s.d) Texto: Guilherme de Almeida (1890-1969)

Lembrança (s.d) Texto: Sarah Markes (s.d)

Matinas (1938) Texto: Sarah Markes (s.d)

5) Canções Populares

Spleen (1965) Texto: Guilherme de Almeida (1890-1969)

Amor, Felicidade (1969) Texto: Guilherme de Almeida (1890-1969)

Pequenino Mundo (1969) Texto: Guilherme de Almeida (1890-1969)

Dor Oculta (1969) Texto: Guilherme de Almeida (1890-1969)

Nota-se que neste conjunto as relações tonais entre as diferentes canções, junto com o tratamento temático, criam uma unidade no discurso musical, realçado pelo fato de o tratamento rítmico remeter a gêneros populares - respectivamente bolero, samba-canção e marcha-rancho - e 
de todos os poemas terem sido tomados do mesmo autor, sendo todos postos em música no mesmo período. Tais aspectos nos dão argumentos para considerá-lo um ciclo.

6) Miniaturas

Vida (s.d) Texto: Suzana de Campos (1884-1945)

Tudo se Acaba (1927) Texto: Alberto de Oliveira (1857-1937)

Arte de Amar (s.d) Texto: Vicente de Carvalho (1966-1924)

Amor (s.d) Texto: Menotti del Picchia (1892-1988)

7) Canções Esparsas

Josesinho (1927) Texto: Adolpho Portela (1866-1923)

Cançoneta do Aquário (1942) Texto: Oliveira Ribeiro Neto (1908-1989)

Spés, Última Déa (s.d) Texto: Lorenzo Stechetti (1845-1916)

Sonata sin nombre (s.d) Texto: Amália Fernandes (s.d)

Saudade (1927) Texto: Plínio dos Santos (s.d)

8) Brasilienses

Canção Sem Importância (1959) Texto: Guilherme de Almeida (1890-1969)

Ciranda, Cirandinha (1934) Texto: Menotti del Picchia

(1892-1988)

Ansiedade (1936) Texto: L. Romanowsky (s.d)

9) Outras canções

Pai João (1946) Texto: Oscar Guanabarino (1851-1937) Pseudônimo: Mattos Alem

Minha Ama (s.d) Texto: Luiz Peixoto (1851-1937)

Malvadinha (s.d) Texto: Benjamim Barreto da Silva Araújo (1902-1985)

Rosinha das Rendas (s.d) Texto: Pedro Astenori Marigliani (19041967) Pseudônimo: Capitão Barduíno.

Folha de Outono (1945) Texto: Murillo Antunes Alves (1919-2010)

e Osvaldo Moles (1913-1967)

Só Você (1931) Texto: Maria Branca Ortega (1910-1990)

Soldados Verdes (1950) Texto: Cassiano Ricardo (1895-1974)

É Bom Que Dói (s.d) Texto: Benjamim Barreto da Silva Araújo (1902-1985) 


\section{Conclusões}

O cancioneiro de Benjamin Barreto da Silva Araújo mostra-se hoje ao mundo musical como território praticamente inexplorado, aguardando para revelar riquezas musicais e poéticas do universo artístico deste compositor brasileiro. Sendo uma obra produzida num período largo e importante da produção musical do país, pode-se perceber que o desconhecimento deste repertório nos mostra o quanto ainda há se desvendar do nosso cenário musical no século $\mathrm{XX}$, principalmente no que se refere à arte da canção de câmera, que é das nossas formas mais antigas e longevas, pois continua viva e pulsante no estro de compositores nossos contemporâneos por todo o Brasil.

Fica claro para nós que se trata de um cancioneiro que deve figurar, pela sua qualidade artística e acabamento formal, entre as obras visitadas por nossos cantores e pianistas cameristas. Há canções de grande complexidade de linguagem, que retratam um ambiente de fazer musical cultivado e grande aprofundamento na linguagem do poema cantado, mas há também exemplos de páginas singelas, que herdam diretamente dos gêneros populares, dos poetas e cantores de seresta, choro e samba-canção o seu encanto simples e direto. Nosso trabalho, como pesquisador e intérprete, segue no sentido de viabilizar a melhor apresentação deste material, acrescido de análises mais amplas, em publicações que possam ser compartilhadas e acessadas por intérpretes, professores e musicólogos. 


\section{Sobre o autor}

\section{Lenine Alves dos Santos}

Cantor, professor e pesquisador. Possui doutorado pela Universidade Estadual Paulista (Unesp). E-mail: leninealves@gmail.com

\section{Nota de Apoio}

O autor desenvolve, com apoio da Fapesp, o projeto de pesquisa de pós-doutoramento "A canção de Benjamin Barreto da Silva Araújo - resgate da obra vocal de um compositor brasileiro." 